\title{
Limites do Novo Consenso Macroeconômico e Surgimento de uma Macroeconomia Financeira
}

Limits of the New Consensus in Macroeconomics and the Emergence of a Financial Macroeconomics

\author{
Saulo de Arruda Alencar ${ }^{\mathrm{a}}$ \\ Leonardo Flauzino de Souzab
}

\begin{abstract}
Resumo: O objetivo deste artigo é descrever e analisar as políticas fiscais e monetárias adotadas pelos EUA no período de 2000 a 2017, sob a ótica do Novo Consenso Macroeconômico (NCM) estabelecido por autores novo-keynesianos, evidenciando ao leitor os elementos ausentes no NCM capazes de explicar a crise financeira de 2008. Os resultados obtidos indicam que é o elevado nível de endividamento privado, e não público, o elementochave das crises econômicas e que contribui para explicar a realidade e as relações financeiras entre os agentes econômicos nos EUA.
\end{abstract}

Palavras-chave: Crise; Política Fiscal; Monetária; Dívida Pública; Privada e Taxa de Juros. Classificação JEL: E12; E52; E62

\begin{abstract}
The main purpose of this paper is to describe and analyze the fiscal and monetary policies adopted by the USA in the period from 2000 to 2017, based on the New Macroeconomic Consensus (NCM) established by New Keynesian authors, showing to the reader the missing elements in the NCM capable of explain the financial crisis of 2008. The results indicate that the high level of private - not public - debt is the key element of economic crises which contributes to explain the reality and financial relations among economic agents in the United States.
\end{abstract}

Keywords: Crisis; Fiscal and Monetary Policy; Public and Private Debt; Interest Rate. JEL Classification: E12; E52; E62

\footnotetext{
${ }^{\text {a }}$ Bacharel em Ciências Econômicas pela Universidade Federal de Mato Grosso.

E-mail: saulo.arrudaalencar@gmail.com

${ }^{\text {b }}$ Professor da Faculdade de Economia da Universidade Federal de Mato Grosso.

E-mail: leo.flauzino@gmail.com
} 


\section{Introdução}

A crise financeira iniciada nos EUA em 2008 demonstrou as fragilidades no sistema financeiro norte-americano e internacional, seus potenciais riscos sistêmicos e seus mecanismos de supervisão e regulação, principalmente no que tange o mercado de derivativos. Diversas medidas fiscais e monetárias foram adotadas pelos Estados Unidos numa tentativa de dirimir os efeitos dessa crise financeira e bancária de grandes proporções.

O objetivo deste artigo é descrever e analisar as políticas fiscais e monetárias adotadas pelos EUA no período de 2000 a 2017, sob a ótica do Novo Consenso Macroeconômico (NCM) estabelecido por autores novo-keynesianos, evidenciando ao leitor os elementos ausentes no NCM capazes de explicar os impactos da crise financeira de 2008.

O NCM foi consolidado em um modelo econométrico de três equações com o intuito de administrar as variações na demanda agregada e os preços a curto prazo (WOODFORD, 2008, 2009). Trabalhos recentes demonstraram que no pós-crise o modelo do NCM não sofreu modificações significativas e ainda permanece como a principal referência para a execução de políticas monetárias pelos bancos centrais (PEDROSA, FARHI, 2015). No entanto, sugere-se que o modelo deva reincorporar elementos importantes que possibilitem a retomada da utilização de políticas fiscais anticíclicas (BLANCHARD, SUMMERS, 2017).

Nesse aspecto, o presente trabalho se diferencia em relação aos anteriores por ser capaz de apontar os elementos essenciais para a compreensão das crises financeiras, como as variáveis não analisadas pelo NCM que tornam esta análise possível, fazendo um levantamento bibliográfico de autores que construíram modelos alternativos ao NCM e mais condizentes com a realidade econômica atual.

Assim, além desta introdução e da conclusão, o artigo apresenta-se dividido em três seções. A primeira evidenciará os principais elementos do NCM; a segunda fará uma análise da economia norte-americana de 2000 a 2017 à luz das interpretações dessa vertente teórica expondo as escolhas de política econômica; e a terceira apresentará os elementos ausentes no NCM que contribuem para a explicar a crise de 2008, suas principais consequências e os reais problemas da atualidade.

\section{As Origens do Novo Consenso Macroeconômico}

A partir da década de 1980, a maioria das pesquisas econômicas tiveram como foco as escolas econômicas Novo-Clássica e Novo-Keynesiana (PEDROSA; FARHI, 2015). Essa última apresentou ainda uma mudança: a introdução das falhas de mercado em seu modelo capazes de criarem rigidezes que dificultam os ajustes de preços necessários para a convergência ao equilíbrio desses modelos. Ao longo dos anos, as ideias macroeconômicas dos Novo-Keynesianos consolidaram-se como corrente principal dentro de um conjunto de princípios que ficou conhecido como Novo Consenso Macroeconômico 
(NCM) ou Nova Síntese Neoclássica (GOODFRIEND; KING, 1997; WOODFORD, 2008, 2009).

Assim, diversas práticas governamentais e dos Bancos Centrais foram tomadas tendo como base as convicções difundidas pelo NCM, especialmente a partir dos anos 1990. De modo geral, os Novo-Keynesianos incorporam a estrutura Novo-Clássica baseada na teoria dos Ciclos Reais de Negócios, nos modelos de Equilíbrio Geral Estocástico e Dinâmico e na Hipótese de Expectativas Racionais (PEDROSA; FARHI, 2015; STIGLITZ, 2011). Todavia, os Novo-Keynesianos, diferente dos Novo-Clássicos, levam em consideração falhas de mercado, rigidez de preços e salários nominais, competição monopolística e assimetria de informações entre os agentes econômicos (WASMER; WEIL, 2004).

Os principais aspectos normativos dos Novo-Keynesianos estão presentes em três equações: na equação de oferta agregada; na equação de demanda agregada e na equação da Regra de Taylor (PEDROSA; FARHI, 2015; WOODFORD, 2003, 2008). A equação de oferta agregada, de acordo com Woodford (2008), evidencia o impacto do nível de preços sobre o produto, como demonstra a equação econométrica abaixo:

$$
\pi_{t}-\overline{\pi_{t}}=\beta_{0} \log \left(\frac{Y_{t}}{Y_{n_{t}}}\right)+\beta_{1}\left(\pi_{t+1}^{e}-\overline{\pi_{t+1}^{e}}\right)+u_{t}
$$

Onde $\pi_{t}$ representa a inflação corrente; $\overline{\pi_{t}}$ a meta de inflação (ou inflação tendencial) corrente; $Y_{t}$ o nível de produto corrente; $Y_{n_{t}}$ o nível natural de produto (ou produto potencial); $\pi_{t+1}^{e}$ a inflação esperada no próximo período; $\overline{\pi_{t+1}^{e}}$ a meta de inflação (ou inflação tendencial) esperada no próximo período; e $u_{t}$ o erro aleatório (ou choques exógenos não previstos).

A Equação 1 demonstra $(i)$ o quanto a inflação deve acelerar-se se o produto passar a crescer acima de seu nível natural (valor máximo de produto a pleno emprego), o qual é definido pela função de produção agregada ${ }^{1}$ que sofre transformações de acordo com os ciclos reais de negócios; e (ii) o quanto a expectativa de inflação futura influencia o nível de inflação corrente em razão das expectativas racionais dos agentes capazes de antecipar reajustes de preços futuro a tempo corrente.

A equação de demanda agregada pode ser definida como:

$$
\log \left(\frac{Y_{t}}{Y_{n_{t}}}\right)=\sigma_{0} \log \left(\frac{Y_{t+1}^{e}}{Y_{n_{t+1}}^{e}}\right)-\sigma_{1}\left(i_{t}-\pi_{t+1}^{e}-r_{t}\right)
$$

onde $Y_{t+1}^{e}$ representa o produto esperado do próximo período; $Y_{n_{t+1}}^{e}$ o produto natural esperado para o próximo período; $i_{t}$ a taxa nominal de juros corrente; e $r_{t}$ a taxa natural de

\footnotetext{
${ }^{1}$ A função de produção agregada pode ser definida como $Y_{n_{t}}=A_{t} K_{t}^{\alpha} N_{t}^{(1-\alpha)}$; sendo que $A_{t}$ representa o nível de tecnologia exógena, $K_{t}$ o estoque de capital corrente e $N_{t}$ o nível de emprego corrente. A tecnologia se modifica de acordo com choques exógenos extraídos dos ciclos reais de negócios, o estoque de capital cresce de acordo com o incremento líquido de investimento e o emprego corrente depende do equilíbrio do mercado de trabalho.
} 
juros $^{2}$ a tempo corrente. A Equação 2 mostra $(i)$ o quanto a expectativa de produto futuro impacta no produto corrente, podendo ser interpretado como transferência de crescimento futuro para tempo corrente ou vice-versa; e (ii) o quanto o diferencial de juros pode contribuir para o crescimento corrente, sendo que quanto menor a taxa de juros, maiores os impactos sobre o produto corrente.

Por fim, acrescenta-se ao modelo uma equação de reação da taxa de juros (Equação 3) com o intuito de administrar a demanda agregada (Equação 2), a fim de evitar impactos inflacionários resultantes do nível de produto estar acima de seu valor natural ou potencial e/ou da expectativa da inflação estar acima da meta inflacionária definida pelo Banco Central, como mostrado pela oferta agregada (Equação 1):

$$
i_{t}=r_{t}+\overline{\pi_{t}}+\gamma_{1} \log \left(\frac{Y_{t}}{Y_{n_{t}}}\right)+\gamma_{2}\left(\pi_{t}-\overline{\pi_{t}}\right)
$$

A Equação 3 evidencia como se deve comportar a taxa de juros como principal, e praticamente único instrumento de administração da demanda agregada. Logo, se a inflação corrente for equivalente à meta $\left(\pi_{t}-\overline{\pi_{t}}\right)$ e o produto corrente equivalente ao natural $\left(Y_{t}=\right.$ $Y_{n_{t}}$ ), a taxa nominal de juros será equivalente à taxa natural somada à inflação corrente, ou seja, a taxa real de juros (taxa nominal de juros descontada a inflação) será equivalente à taxa natural, deixando o sistema em um equilíbrio hipotético.

Assim sendo, nota-se que há uma busca de um nível adequado da taxa de juros para manter a inflação dentro da meta. Antes da crise econômica de 2008, para garantir a estabilidade da inflação como uma pré-condição para o crescimento da produção no longo prazo, o Banco Central buscava a estabilidade dos preços. Logo, o Banco Central fazia uso da taxa de juros no curto prazo como único mecanismo de controle de preços. Cabe salientar que essa estrutura de política monetária estava concebida em um Banco Central independente, com características técnicas sólidas, sem regulação dos preços, bem como baixa sensitividade do preço das commodities aos choques de mercado (WOODFORD, 2003).

Em relação ao mercado financeiro, frisa-se que a intermediação financeira não tinha relevância macroeconômica antes da crise, mesmo com o processo de alavancagem ou de exposição excessiva do mercado, de modo que a regulação financeira não era considerada um instrumento de política macroeconômica (PASINETTI, 2012). Além disso, a regulação existente antes da crise estava focada em instituições bancárias, não no mercado financeiro como um todo (FARHI, 2011).

Segundo Pasinetti (2012), a ideia de um sistema financeiro neutro remete à hipótese Modigliani-Miller (MODIGLIANI; MILLER, 1958), a qual considera irrelevante a forma como os agentes econômicos privados optam por se financiarem. Para a validade desse pressuposto, é necessário considerar um mercado financeiro perfeito - sem custos de

\footnotetext{
${ }^{2}$ A taxa natural de juros é a que equilibra mercado de financiamento, ofertantes e demandantes de fundos, ou seja, a taxa de juros que não acelera a inflação corrente.
} 
transação e sem informação assimétrica - e a presença de agentes econômicos racionais maximizadores da função utilidade da riqueza (MILLER; MODIGLIANI, 1961).

Ao adotar tais hipóteses, a regulação financeira torna-se secundária e até mesmo desnecessária (FAMA, 1980). O atributo liquidez dos ativos passa a ter menos importância e os agentes financeiros e bancários - atuando na sua função exclusiva de intermediação financeira - passam a competir entre si por meio de serviços oferecidos ao público (GURLEY; SHAW, 1955, 1956). Assim, esse sistema financeiro neutro atua apenas como um canal de transmissão da política monetária, de tal forma que as elevações e reduções na taxa de juros controlada pelo Banco Central são transmitidas pelas demais taxas de juros de mercado (FONTANA, 2007).

Ao abordar a política fiscal, Pedrosa e Farhi (2015) ressaltam que ela é bem menos discutida do que a política monetária. Entre os motivos, estão $(i)$ a dificuldade da política fiscal em desenvolver mecanismos para dirimir o caráter discricionário que é predominante nos gastos públicos; (ii) o fato do modelo dinâmico estocástico de equilíbrio geral ser voltado para a ótica das famílias, considerando muito pouco os aspectos fiscais, uma vez que o modelo não diferencia gastos públicos dos privados; e (iii) a falta de convergência teórica dos economistas sobre o assunto.

Os autores ressaltam ainda que os economistas do NCM ignoraram a política fiscal como um instrumento oportuno e como um mecanismo central de política anticíclica por uma série de fatores, como o ceticismo sobre a eficácia de políticas fiscais, especialmente nos resultados de atividades econômicas de curto prazo; a capacidade da política monetária manter o nível de produção estável; o risco do hiato entre a adoção da política fiscal e a recuperação econômica ser maior do que o próprio período recessivo; e as divergências políticas inerentes às aprovações e implantações de políticas fiscais. Assim sendo, o NCM optou por ignorar a política fiscal como um instrumento anticíclico, argumentando que ela seria implementada apenas em situações extremas nas quais a política monetária não surtisse mais efeito.

Os argumentos contrários à adoção de políticas fiscais se concentram na hipótese de Equivalência Ricardiana ou Hipótese Ricardo-Barro (BARRO, 1974, 1989). Ao tratar da análise Ricardiana sobre o "modelo padrão" de déficit público, Barro (1989) argumenta que dado um certo padrão de gastos, o corte de tributos por parte do governo não terá resultado satisfatório, visto que se espera uma elevação da tributação no futuro (no mesmo nível antes de serem realizados os cortes). Logo, o valor atual de tributação e outras formas de arrecadação de receita governamental não podem mudar caso não ocorra modificações nos gastos do governo. Assim sendo, Barro (1989) mostra que a substituição de déficit público corrente por tributação futura não apresenta impacto na demanda agregada por bens, uma vez que os agentes econômicos apenas poupariam mais na antecipação de tributos mais elevados no futuro.

Com o intuito de esclarecer ainda mais a temática da política fiscal, Barro (1974) questiona se os títulos de dívida pública do governo podem ser considerados riqueza privada. Para o autor, o efeito da expansão físcal faz com que os títulos de dívida do governo sejam percebidos como suposta riqueza privada quando eles excedem o valor 
futuro da arrecadação de tributos. Barro menciona que o governo aumentará o nível de riqueza privada caso seja mais eficiente do que o setor privado como tomador de empréstimos (supondo existência de imperfeições de mercado nos mercados financeiros privados).

Desse modo, Barro (1974) considera que não há argumentos persuasivos o suficiente para comprovar que a elevação do nível de dívida pública do governo gera também um aumento no nível de riqueza privada por parte das famílias. Para ele, o mesmo se aplica quando há a suposição de um efeito negativo do crescimento da dívida. $\mathrm{O}$ autor busca mostrar com seus argumentos que a política fiscal pode ser um instrumento econômico que passa estabilidade e previsibilidade para os demais agentes econômicos.

Na tentativa de confirmar as ideias levantadas por Barro $(1974,1989)$, Reinhart e Rogoff (2010) realizaram um estudo econométrico demonstrando que elevados níveis de dívida pública teriam correlação com baixos níveis de crescimento. No entanto, Herndon et al. (2014) evidenciaram erros na metodologia utilizada pelos autores e a impossibilidade de se atingir resultados conclusivos com base nos dados analisados.

Por outro lado, a política fiscal pode ser um importante instrumento de controle inflacionário em economias abertas com déficits crônicos em transações correntes e elevadas taxas de juros voltadas para suprir a necessidade de financiamento externo. Nesses casos, a administração de déficits públicos e da razão dívida por PIB torna-se um instrumento mais relevante do que a administração da taxa de juros como política desinflacionária (BLANCHARD, 2004).

Portanto, o modelo do NCM é sustentado por três grandes pilares: $(i)$ política monetária voltada para a administração da inflação de demanda (TAYLOR, 1993; WOODFORD, 2008); ( $\mathrm{ii}$ ) sistema financeiro neutro que atua apenas como intermediador entre agentes deficitários e superavitários (FAMA, 1980; GURLEY; SHAW, 1956); (iii) e política fiscal ineficaz e voltada para a administração de déficits e razão dívida por PIB (BARRO, 1974, 1989; BLANCHARD, 2004).

\section{Política Econômica nos EUA de 2000 a 2017}

O presente trabalho utiliza-se do método de pesquisa descritiva para comparar os conceitos explicitados com os dados da economia norte-americana. Para a análise, foi considerado o período de 2000 a 2017, uma vez que o ano de 2000 ocorreu a crise das ponto-com, primeira crise em um país não emergente a levantar questionamentos sobre as políticas econômicas adotadas pelo NCM; e 2017 é o último ano da série histórica disponível. É importante salientar que a literatura econômica considera que o mundo ainda vive os efeitos da grande recessão, embora alguns países estejam mais estáveis que outros (BLANCHARD; SUMMERS, 2017).

Com o objetivo de exemplificar e analisar as medidas monetárias e fiscais adotadas pelos Estados Unidos para combater a crise financeira, retomam-se os argumentos de Predrosa e Farhi (2015). Os autores revisam algumas publicações realizadas por importantes economistas da corrente Novo-Keynesianos após o agravamento da crise 
financeira. Nesse sentido, notam-se que algumas falhas desse modelo normativo foram reconhecidas, bem como novas características teóricas foram propostas.

Algumas imperfeições no modelo teórico dos Novo-Keynesianos foram identificadas, de forma que, três incorreções foram destacadas após a piora da crise: $(i)$ o fato da taxa de juros nominal no curto prazo ser estabelecida em um baixo nível nos países desenvolvidos; (ii) o fato da política fiscal não ser considerada, até aquele período, como uma ferramenta anticíclica de relevância; (iii) e a não neutralidade do mercado financeiro e das regulações macroeconômicas pertinentes a esse sistema (BLANCHARD; DELL'ARICCIA; MAURO, 2010). Nesse mesmo documento, os autores enfatizam o papel das instituições financeiras como propagadoras da crise, havendo, nesse caso, a necessidade de o Banco Central solucionar a falta de liquidez para evitar o que o autor classifica como "espiral deflacionária".

De forma semelhante ao anteriormente mencionado, Blanchard et al. (2010) argumenta que, antes da crise, a política fiscal exercia um papel secundário e pensava-se que a regulação financeira não fazia parte da estrutura de políticas macroeconômicas. Para o autor, os motivos para a política fiscal não ter sido tão utilizada nas duas décadas que antecederam a crise são: o ceticismo em relação aos efeitos de tal política, baseando-se nos argumentos de equivalência Ricardiana; o receio de elevar a dívida pública, ainda em um cenário no qual as oscilações econômicas eram aparentemente de curta duração e as medidas fiscais que se apresentavam tardias.

No que concerne a política monetária, ela tinha um único objetivo de acordo com Blanchard et al. (2010): a inflação estável. Tal finalidade encontrava suporte intelectual nos argumentos dos Novo-Keynesianos (WOODFORD, 2003, 2009). Para alcançar esse propósito, utilizava-se da política de taxa de juros, de modo que a inflação se manteve estável nos anos que antecederam a crise, conforme a tabela abaixo.

A Tabela 1 sumariza as principais variáveis envolvidas nas decisões de política monetária segundo o novo consenso macroeconômico. Após o estouro da bolha financeira das empresas ponto-com em 2000, a taxa de crescimento do PIB reduziu significativamente, de mais de $4 \%$ em 2000 para menos de $1 \%$ em 2001, e a taxa de desemprego se elevou em quase dois pontos percentuais. A literatura econômica associada ao novo consenso tratou de crises financeiras como choques exógenos imprevisíveis e supunha que seus efeitos eram nulos a longo prazo (BRUNNERMEIER; SANNIKOV, 2014; CAIANI et al., 2016).

A política monetária respondeu com redução da taxa de juros entre 2001 e 2003 , obtendo um sucesso modesto na elevação do ritmo de crescimento do PIB, de pouco menos de $1 \%$ para quase $3 \%$; mas sendo incapaz de recuperar o nível de capacidade produtiva utilizada, estabilizada em torno de $75 \%$, e com pouca alteração no nível de desemprego, entre 5,7\% e 6\%. Em razão do baixo nível e modesto crescimento do PIB e desemprego mais elevado, a inflação manteve-se estável em torno de $2 \%$. Nesse sentido, para os formuladores de política econômica do NCM, a economia norte-americana estava apenas absorvendo um choque exógeno causada por uma crise financeira local sem impactos a longo prazo. 
Tabela 1 - EUA: Principais Variáveis Macroeconômicas para o NCM - 2000 a 2017

\begin{tabular}{c|c|c|c|c|c|c}
\hline \hline Ano & $\begin{array}{c}\text { Taxa de } \\
\text { juros }\end{array}$ & $\begin{array}{c}\text { Base } \\
\text { Monetária } \\
\text { por PIB }\end{array}$ & Inflação & Desemprego & $\begin{array}{c}\text { Capacidade } \\
\text { Produtiva } \\
\text { Utilizada }\end{array}$ & $\begin{array}{c}\text { Crescimento } \\
\text { do PIB }\end{array}$ \\
\hline 2000 & $6,24 \%$ & $5,82 \%$ & $3,36 \%$ & $3,90 \%$ & $81,40 \%$ & $4,09 \%$ \\
\hline 2001 & $3,88 \%$ & $6,13 \%$ & $2,85 \%$ & $5,70 \%$ & $76,10 \%$ & $0,98 \%$ \\
\hline 2002 & $1,67 \%$ & $6,37 \%$ & $1,58 \%$ & $6,00 \%$ & $74,90 \%$ & $1,79 \%$ \\
\hline 2003 & $1,13 \%$ & $6,42 \%$ & $2,28 \%$ & $5,70 \%$ & $75,90 \%$ & $2,81 \%$ \\
\hline 2004 & $1,35 \%$ & $6,32 \%$ & $2,66 \%$ & $5,40 \%$ & $78,10 \%$ & $3,79 \%$ \\
\hline 2005 & $3,22 \%$ & $6,13 \%$ & $3,39 \%$ & $4,90 \%$ & $80,00 \%$ & $3,34 \%$ \\
\hline 2006 & $4,97 \%$ & $5,97 \%$ & $3,23 \%$ & $4,40 \%$ & $80,40 \%$ & $2,67 \%$ \\
\hline 2007 & $5,02 \%$ & $5,78 \%$ & $2,85 \%$ & $5,00 \%$ & $80,70 \%$ & $1,78 \%$ \\
\hline 2009 & $1,92 \%$ & $11,30 \%$ & $3,84 \%$ & $7,30 \%$ & $77,80 \%$ & $-0,29 \%$ \\
\hline 2010 & $0,16 \%$ & $14,10 \%$ & $-0,36 \%$ & $9,90 \%$ & $68,50 \%$ & $-2,78 \%$ \\
\hline 2011 & $0,18 \%$ & $13,50 \%$ & $1,64 \%$ & $9,30 \%$ & $73,60 \%$ & $2,53 \%$ \\
\hline 2012 & $0,14 \%$ & $16,90 \%$ & $3,16 \%$ & $8,50 \%$ & $76,20 \%$ & $1,60 \%$ \\
\hline 2013 & $0,11 \%$ & $22,30 \%$ & $1,46 \%$ & $6,70 \%$ & $77,60 \%$ & $1,68 \%$ \\
\hline 2015 & $0,09 \%$ & $22,60 \%$ & $1,62 \%$ & $5,60 \%$ & $79,00 \%$ & $2,57 \%$ \\
\hline 2016 & $0,13 \%$ & $21,20 \%$ & $0,12 \%$ & $5,00 \%$ & $77,30 \%$ & $2,86 \%$ \\
\hline 2017 & $1,00 \%$ & $19,90 \%$ & $2,13 \%$ & $4,10 \%$ & $76,10 \%$ & $2,27 \%$ \\
\hline \hline
\end{tabular}

Fonte: Federal Reserve, Bureau of Labor Statistics, Bureau of Economic Analysis; Elaboração Própria.

A recuperação mostrou-se mais vigorosa em 2004 e 2005, sendo que a elevação da inflação, para mais de $3 \%$, foi acompanhada por elevações na taxa de juros, de 1,35\% para mais de 3\%, como forma de conter o nível de crescimento, que iniciou uma trajetória de queda. $\mathrm{O}$ aumento temporário do crescimento e da inflação foram acompanhados de uma pequena redução no desemprego, para pouco menos de $5 \%$, e o aumento da capacidade produtiva utilizada, para pouco mais de $80 \%$.

Segundo o NCM, a aceleração da inflação no curto prazo é reflexo do aquecimento da economia além de seu nível natural ou potencial, caracterizado por pressões no mercado de trabalho com a redução do desemprego e na atividade industrial com o aumento da capacidade produtiva utilizada (ALVES; CORREA, 2013). A longo prazo, a tendência de elevação do nível de inflação é consequência da expansão da base monetária e outros agregados monetários (WOODFORD, 2009), que se mostrou estável entre 2000 e 2007, seguindo os preceitos do NCM.

Os anos de 2006 e 2007 representam os últimos anos de estabilidade. A elevação da taxa de juros começava a estabilizar a inflação via aumento do desemprego e redução da atividade econômica. Por outro lado, a elevação da taxa de juros foi gradativamente elevando os empréstimos de baixa de qualidade, levando ao aumento significativo da inadimplência e ao estouro da crise financeira de 2008 (FARHI; CINTRA, 2009; PRATES; FARHI, 2015; SOUZA, 2016). 
Este é precisamente um dos elementos ignorados pelo NCM, que será melhor trabalhado na próxima seção, que passam a ter impactos econômicos reais para além de choques econômicos exógenos e, supostamente, sem impactos a longo prazo. Em uma revisão crítica dos modelos do NCM, Brunnermeier e Sannikov (2014) propõem que crises financeiras podem alterar o crescimento futuro da produtividade e do PIB potencial, no entanto, em nada modificam a estrutura das políticas econômicas desenvolvidas pelo Novo Consenso.

A partir de 2008, observa-se pela Tabela 1, que a inflação permaneceu em patamares muito baixos, mesmo com a explosão da base monetária; a taxa de juros ficou próxima da nulidade; e o desemprego, após o pico em 2009, iniciou uma trajetória de queda. Por uma década, a política monetária usual do NCM evitou uma depressão econômica, mas não foi capaz de gerar retomada do crescimento ao mesmo nível médio observado de 2000 a 2006, levantando dúvidas sobre sua real eficácia (BLANCHARD; DELL'ARICCIA; MAURO, 2013; BLANCHARD; SUMMERS, 2017; PEDROSA; FARHI, 2015).

É importante mencionar que a expansão da base monetária, de 2008 a 2014 (Tabela 1), não faz parte das políticas econômicas convencionais do NCM. Nesse período, o Banco Central norte-americano adotou políticas não convencionais, como o Quantitative Easing, que envolviam a expansão da base monetária e a redução das taxas de juros a longo prazo. Em essência, o Quantitative Easing se resume a compras massivas de títulos públicos a longo prazo por parte do Banco Central, forçando as taxas de juros para baixo e expandindo a base monetária e o balanço patrimonial do Federal Reserve (CÚRDIA; WOODFORD, 2011).

Para Cúrdia \& Woodford (2011) tais políticas podem se justificar devido a imperfeições de mercado no sistema de intermediação financeira; ou em momentos em que a autoridade monetária sinaliza aos agentes privados que as taxas de juros de curto prazo irão se manter aquém do nível de equilíbrio definido pela Regra de Taylor por um período mais longo que o usual. No entanto, na presença de mercados perfeitos, os autores afirmam que as políticas não convencionais de expansão da base monetária - como o Quantitative Easing - não teriam qualquer impacto sobre a demanda agregada.

Os efeitos deletérios da combinação de uma política monetária convencional de manutenção das taxas de juros de curto prazo baixas com expansão da base monetária ficaria restrita à geração de novas bolhas de ativos (BLANCHARD; SUMMERS, 2017). No entanto, os autores admitem que o NCM da forma como é estruturado não é capaz de formular uma resposta aos ciclos de inflação de deflação de ativos financeiros. O modelo de Cúrdia e Woodford (2011), apesar de adicionar o papel da intermediação financeira, mantém-na realizada exclusivamente por bancos sem a incorporação de preços de ativos ou agentes financeiros não bancários.

A política fiscal, como discutido na seção anterior, ficou restrita às políticas de controle do déficit fiscal voltadas para a manutenção da estabilidade da razão da dívida pública por PIB em diferentes patamares, antes e após a crise de 2008. Como pode ser observado pelo Gráfico 1, há expansão do déficit fiscal em momentos de crise econômica e elevação da razão dívida por PIB (de 2000 a 2003 com a crise acionária das empresas 
ponto-com em 2000; e de 2008 a 2010 em razão da crise financeira do setor imobiliário); e momentos de estabilização dos déficits e relativa constância da razão dívida por PIB (de 2004 a 2007; e 2011 a 2017).

\section{Gráfico 1: EUA: Dívida Pública por PIB e Resultado Financeiro Consolidado do Governo de 2000 a 2017}

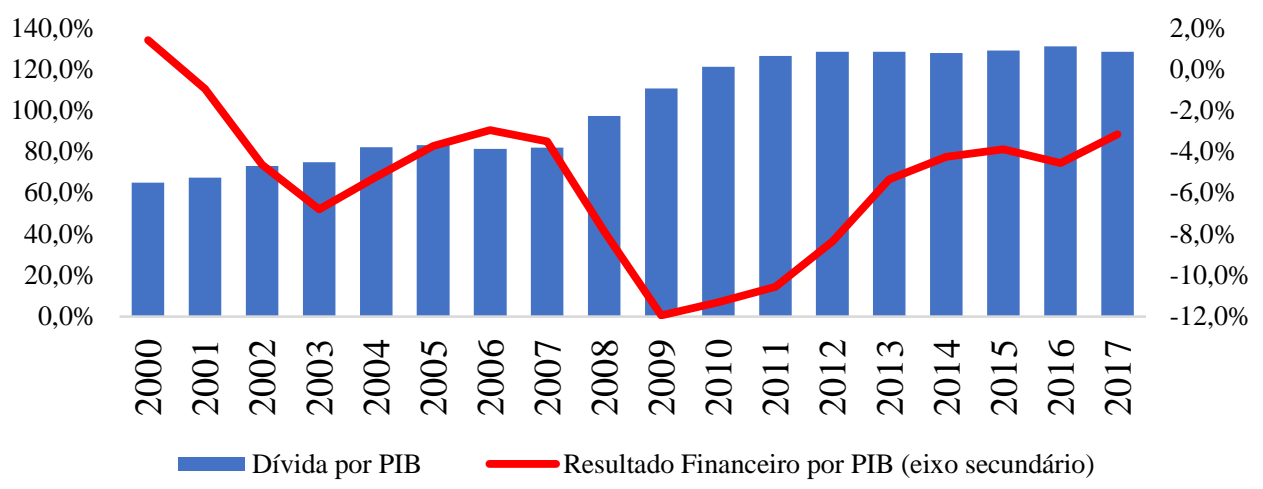

Fonte: Federal Reserve; Elaboração Própria.

O Gráfico 1 evidencia que em 2009 atingiu-se o valor mais elevado de déficit fiscal e trajetória de explosão da razão dívida por PIB em razão dos programas voltados à compra de ativos considerados podres nos mercados financeiros e a uma política fiscal modesta de sustentação da demanda, contrariando as práticas usuais do NCM. No entanto, isso já foi suficiente para que economistas associados ao NCM mostrassem preocupações com o ritmo de crescimento da dívida (HERNDON; ASH; POLLIN, 2014; REINHART; ROGOFF, 2010), reorientando a política fiscal para a redução do déficit fiscal e estabilização da razão dívida por PIB em um novo patamar.

Mecanismos para dirimir os impactos da crise financeira foram propostos por Blanchard (2010), como a implementação de estruturas de política fiscal de médio prazo; compromisso em reduzir efetivamente a relação dívida por PIB e melhorias nas formas de arrecadação tributária e outras formas de geração de receitas governamentais a longo prazo. No tocante à rigidez de gastos governamentais proposta pelo autor, frisam-se os "estabilizadores automáticos" (BLANCHARD, 2010, p. 16), como a tributação progressiva e a criação temporária de tributos para setores específicos da sociedade em momentos de choques econômicos. Dessa maneira, Blanchard (2010) apresenta um panorama promissor de recuperação econômica, e argumenta que a política monetária tradicional, juntamente com a melhoria dos estabilizadores automáticos da política físcal são as propostas a serem colocadas em prática.

Contudo, Blanchard et al. (2013) revela uma perspectiva incerta do cenário de recuperação econômica, mesmo após várias pesquisas e políticas monetárias e físcais terem sido colocadas em prática pelo então governo Obama. O autor ressalta a previsão do retorno do estabelecimento de metas inflacionárias mais flexíveis, com a utilização, ainda que 
pequena, de política fiscal com o propósito de estabilização econômica. Blanchard e Summers (2017) novamente enfatizam a necessidade de políticas fortes de estabilização como fatores cruciais para reagir de maneira enérgica aos choques econômicos. Porém, diferentemente das afirmações anteriores, os autores propõem agora uma visão mais branda em relação ao crescimento da relação dívida por PIB.

Apesar da autocrítica realizada por Blanchard e Summers (2017), admitindo a incapacidade dos pressupostos do NCM em lidar com crises financeiras e relevando a necessidade de uma política fiscal mais ativa com mecanismos de controle da razão dívida por PIB mais brandos, não houve grandes modificações na estrutura dos modelos do NCM nem nas recomendações de política econômica, como ressaltam Farhi e Pedrosa (2015).

\section{Macroeconomia Financeira: Os Elementos Ausentes do NCM}

O potencial fracasso da políticas econômicas associadas ao NCM foram responsáveis pelo rápido crescimento de um literatura voltada a melhor compreender a relação entre as variáveis financeiras e as decisões de gasto agregado dos agentes econômicos (NIKIFOROS; ZEZZA, 2017). Novos modelos econômicos emergiram em contraste com os modelos de equilíbrio geral, permitindo análises mais complexas que envolvam a transmissão de efeitos intertemporais sequenciais - sem uso de estática comparativa - e cumulatividade das decisões tomadas pelos agentes econômicos (DOSI $e t$ al., 2015; FAGIOLO; ROVENTINI, 2012).

Os modelos de equilíbrio geral estocástico e dinâmico são incapazes de tornar endógeno a criação de moeda e os ciclos de expansão e restrição de liquidez e crédito (BOYER, 2013; DAVIDSON, 1988). A única forma de eventos de restrição de financiamento serem inseridos nos modelos é por choques aleatórios nas funções de consumo intertemporal ou de decisão de alocação produtiva do fator trabalho, entre horas de lazer não remunerada e horas de trabalho remunerada (BRUNNERMEIER; SANNIKOV, 2014). Nesse aspecto, esses modelos tornam-se inapropriados para a compreensão dos fenômenos macroeconômicos atuais (CAIANI et al., 2016; STIGLITZ, 2011).

Crises financeiras são consequência de processos de endividamento crônico de agentes econômicos (MINSKY, 2008). De forma geral, os processos de endividamento estão associados ao crescimento da demanda agregada, uma vez que os agentes econômicos utilizam de sua capacidade de obter financiamento, e do sistema financeiro em provê-lo, para subsidiar a expansão de componentes da demanda agregada (AMITRANO, 2013; GODLEY, 2012).

Nos últimos anos, cresceu a discussão acerca do processo de financeirização que marca a significativa expansão dos ativos financeiros, que só é possível por meio da expansão dos passivos (dívidas) dos agentes econômicos (SOUZA, 2016). A literatura econômica não associada ao NCM passou a analisar os impactos macroeconômicos de tal processo. As principais conclusões dessa literatura podem ser assim sumarizadas: $(i)$ crescimento e retração dos componentes de demanda de acordo com os ciclos de 
valorização e desvalorização dos ativos (AMITRANO, 2013; BOYER, 2000; COUTINHO; BELLUZZO, 1998); (ii) alterações no regime de acumulação e crescimento da produtividade (HEIN, 2012; STOCKHAMMER, 2004); e (iii) aumento da incidência de crises financeiras e de restrição de liquidez (GUTTMANN, 2015; GUTTMANN; PLIHON, 2010; VAN TREECK, 2009; WRAY, 2009).

$\mathrm{O}$ equacionamento da abordagem acima não pode ser sintetizado em um conjunto de poucas equações, mas pode ser expresso por um conjunto de relações entre variáveis. De forma geral, os resultados financeiros dos agentes econômicos agregados (Gráfico 2) estão vinculados ao crescimento das variáveis de demanda agregada (Tabela 2), implicando em aumento do endividamento dos mesmos agentes (Gráfico 3).

\section{Gráfico 2: EUA: Resultados Financeiros por Agente Econômico Agregado em Razão do PIB de 2000 a 2017}

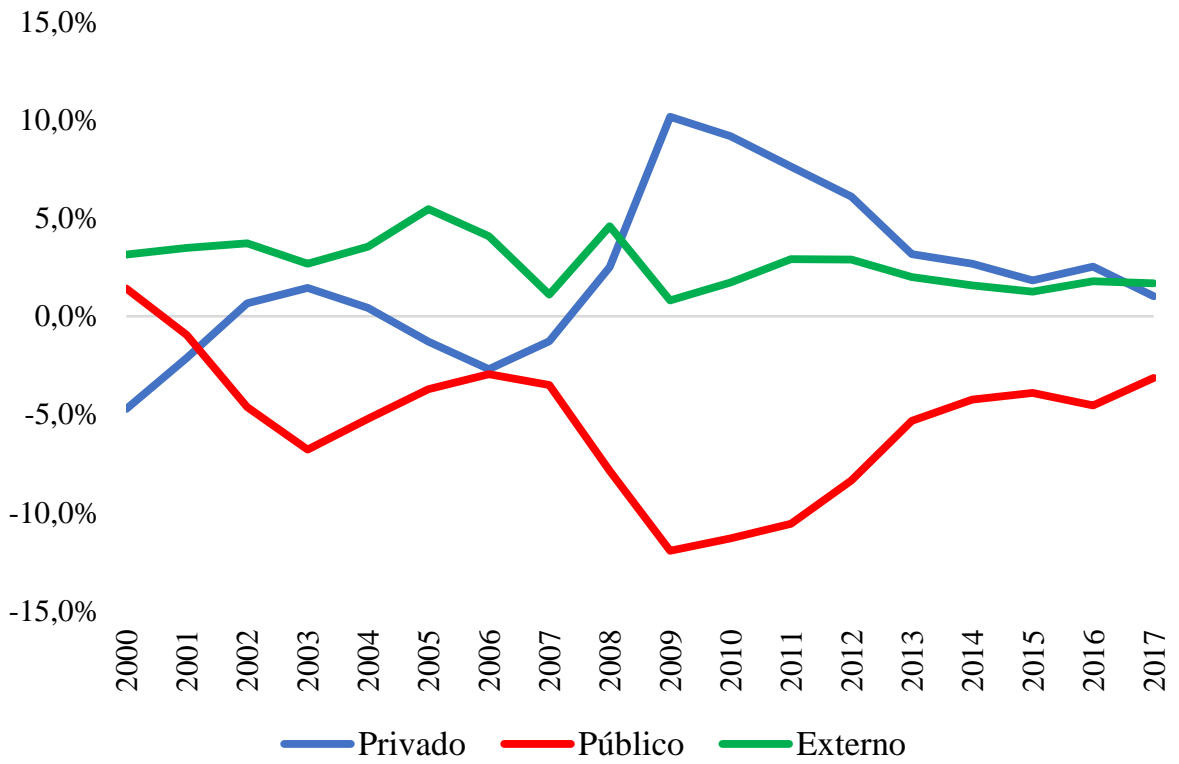

Fonte: Federal Reserve; Elaboração Própria.

O Gráfico 2 demonstra que todos os agentes econômicos (público, privado e externo) em posição deficitária estarão em processos de endividamento crônico, enquanto os agentes superavitários estarão acumulando ativos financeiros. Nesse sentido, o setor público cronicamente deficitário, com exceção de 2000, e o setor externo cronicamente superavitário podem ser enquadrados nos processos acima. No entanto, é o comportamento do setor privado que define a possibilidade de ocorrência de crises financeiras, uma vez que, diferente do setor público, seus déficits terão de ser eventualmente revertidos (GODLEY, 2012). 
Os resultados financeiros acima estão relacionados às oscilações nas variáveis de gasto agregado. A queda dos superávits privados ou a geração de déficits estarão associados à expansão de consumo e investimento, os quais, como evidenciado pela Tabela 2, compõe mais de $80 \%$ do PIB do EUA. De forma análoga, aumento ou redução dos gastos do governo terão impacto de aumentar ou reduzir os déficits públicos. O setor externo atua, para a economia norte-americana, como um fator redutor de demanda, uma vez que o saldo exportador é sempre negativo (Tabela 2), implicando em um setor externo superavitário (Gráfico 2).

\section{Tabela 2: EUA: Crescimento e Proporção da Composição do PIB pela Ótica da Demanda de 2000 a 2017}

\begin{tabular}{c|c|c|c|c|c|c|c|c|c|c}
\hline \hline \multirow{2}{*}{ Ano } & \multicolumn{2}{|c}{ Consumo } & \multicolumn{2}{|c|}{ Investimento } & \multicolumn{2}{c|}{ Gasto do Governo } & \multicolumn{2}{c|}{ Exportac̃os } & \multicolumn{2}{c}{ Importaç̃es } \\
\cline { 2 - 10 } & \%resc. & $\%$ PIB & \% Cresc. & $\%$ PIB & \%Cresc. & $\%$ PIB & \%Cresc. & $\%$ PIB & $\%$ Cresc. & $\%$ PIB \\
\hline 2000 & $5,08 \%$ & $66,0 \%$ & $6,46 \%$ & $19,8 \%$ & $1,90 \%$ & $17,8 \%$ & $8,57 \%$ & $10,7 \%$ & $13,0 \%$ & $14,3 \%$ \\
\hline 2001 & $2,59 \%$ & $66,9 \%$ & $-6,06 \%$ & $18,2 \%$ & $3,77 \%$ & $18,4 \%$ & $-5,84 \%$ & $9,67 \%$ & $-2,84 \%$ & $13,1 \%$ \\
\hline 2002 & $2,58 \%$ & $67,3 \%$ & $-0,59 \%$ & $17,5 \%$ & $4,37 \%$ & $19,1 \%$ & $-1,72 \%$ & $9,13 \%$ & $3,66 \%$ & $13,0 \%$ \\
\hline 2003 & $3,13 \%$ & $67,5 \%$ & $4,08 \%$ & $17,6 \%$ & $2,16 \%$ & $19,3 \%$ & $1,76 \%$ & $9,04 \%$ & $4,47 \%$ & $13,4 \%$ \\
\hline 2004 & $3,84 \%$ & $67,3 \%$ & $8,78 \%$ & $18,5 \%$ & $1,59 \%$ & $19,2 \%$ & $9,75 \%$ & $9,63 \%$ & $11,4 \%$ & $14,7 \%$ \\
\hline 2005 & $3,51 \%$ & $67,2 \%$ & $6,42 \%$ & $19,3 \%$ & $0,64 \%$ & $19,0 \%$ & $6,25 \%$ & $10,0 \%$ & $6,33 \%$ & $15,5 \%$ \\
\hline 2006 & $3,04 \%$ & $67,1 \%$ & $2,15 \%$ & $19,3 \%$ & $1,52 \%$ & $19,1 \%$ & $9,04 \%$ & $10,7 \%$ & $6,32 \%$ & $16,2 \%$ \\
\hline 2007 & $2,24 \%$ & $67,3 \%$ & $-3,15 \%$ & $18,3 \%$ & $1,57 \%$ & $19,4 \%$ & $9,27 \%$ & $11,5 \%$ & $2,52 \%$ & $16,5 \%$ \\
\hline 2008 & $-0,34 \%$ & $68,0 \%$ & $-9,39 \%$ & $16,5 \%$ & $2,76 \%$ & $20,4 \%$ & $5,74 \%$ & $12,5 \%$ & $-2,56 \%$ & $17,4 \%$ \\
\hline 2009 & $-1,60 \%$ & $68,3 \%$ & $-21,6 \%$ & $13,0 \%$ & $3,15 \%$ & $21,4 \%$ & $-8,79 \%$ & $11,0 \%$ & $-13,7 \%$ & $13,8 \%$ \\
\hline 2010 & $1,92 \%$ & $68,2 \%$ & $12,9 \%$ & $14,0 \%$ & $0,07 \%$ & $21,2 \%$ & $11,9 \%$ & $12,4 \%$ & $12,7 \%$ & $15,8 \%$ \\
\hline 2011 & $2,26 \%$ & $68,9 \%$ & $5,19 \%$ & $14,4 \%$ & $-3,04 \%$ & $20,4 \%$ & $6,85 \%$ & $13,6 \%$ & $5,47 \%$ & $17,3 \%$ \\
\hline 2012 & $1,46 \%$ & $68,4 \%$ & $10,6 \%$ & $15,5 \%$ & $-1,86 \%$ & $19,6 \%$ & $3,42 \%$ & $13,6 \%$ & $2,23 \%$ & $17,1 \%$ \\
\hline 2013 & $1,46 \%$ & $68,1 \%$ & $6,12 \%$ & $16,2 \%$ & $-2,86 \%$ & $18,7 \%$ & $3,48 \%$ & $13,6 \%$ & $1,09 \%$ & $16,6 \%$ \\
\hline 2014 & $2,87 \%$ & $68,1 \%$ & $5,55 \%$ & $16,7 \%$ & $-0,65 \%$ & $18,1 \%$ & $4,27 \%$ & $13,6 \%$ & $4,50 \%$ & $16,5 \%$ \\
\hline 2015 & $3,64 \%$ & $68,1 \%$ & $5,20 \%$ & $17,1 \%$ & $1,39 \%$ & $17,8 \%$ & $0,41 \%$ & $12,5 \%$ & $4,96 \%$ & $15,4 \%$ \\
\hline 2016 & $2,73 \%$ & $68,8 \%$ & $-1,62 \%$ & $16,4 \%$ & $0,75 \%$ & $17,5 \%$ & $-0,33 \%$ & $11,9 \%$ & $1,27 \%$ & $14,7 \%$ \\
\hline 2017 & $2,75 \%$ & $69,1 \%$ & $3,29 \%$ & $16,6 \%$ & $0,11 \%$ & $17,3 \%$ & $3,37 \%$ & $12,1 \%$ & $3,95 \%$ & $15,0 \%$ \\
\hline \hline
\end{tabular}

Fonte: Bureau of Economic Analysis; Elaboração Própria.

Pela Tabela 2, observa-se que o crescimento de 2000 a 2007 foi lastreado na expansão do consumo e do investimento, em especial de 2003 a 2006. No mesmo período, observa-se que o déficit exportador se ampliou e o governo passou a gradativamente controlar a expansão dos gastos, reduzindo os déficits públicos. Em 2008 e 2009, a queda do PIB (Tabela 1) foi consequência da queda do consumo e investimento (Tabela 2), minimizado por uma expansão moderada dos gastos do governo (Tabela 2). A significativa expansão dos déficits públicos nesse período (Gráfico 2), que elevou os superávits privados, foi consequência dos programas de compra de ativos podres e da capitalização direta de empresas e bancos com problemas de liquidez e solvência (FARHI; CINTRA, 2009).

De 2010 a 2017, observaram-se o crescimento moderado do consumo e aumento significativo do investimento e a gradativa redução do crescimento dos gastos públicos, reduzindo os déficits públicos e, por consequência, diminuindo os superávits privados. Processo que, segundo Godley (2012), tende a ser revertido de maneira crítica ou hard 
landing por meio de uma crise econômica, ou de maneira amena ou soft landing por uma estagnação econômica.

\section{Gráfico 3: EUA: Relação de Passivos Totais (Incluindo Capital de Terceiros) por Agente Econômico Agregado de 2000 a 2017}

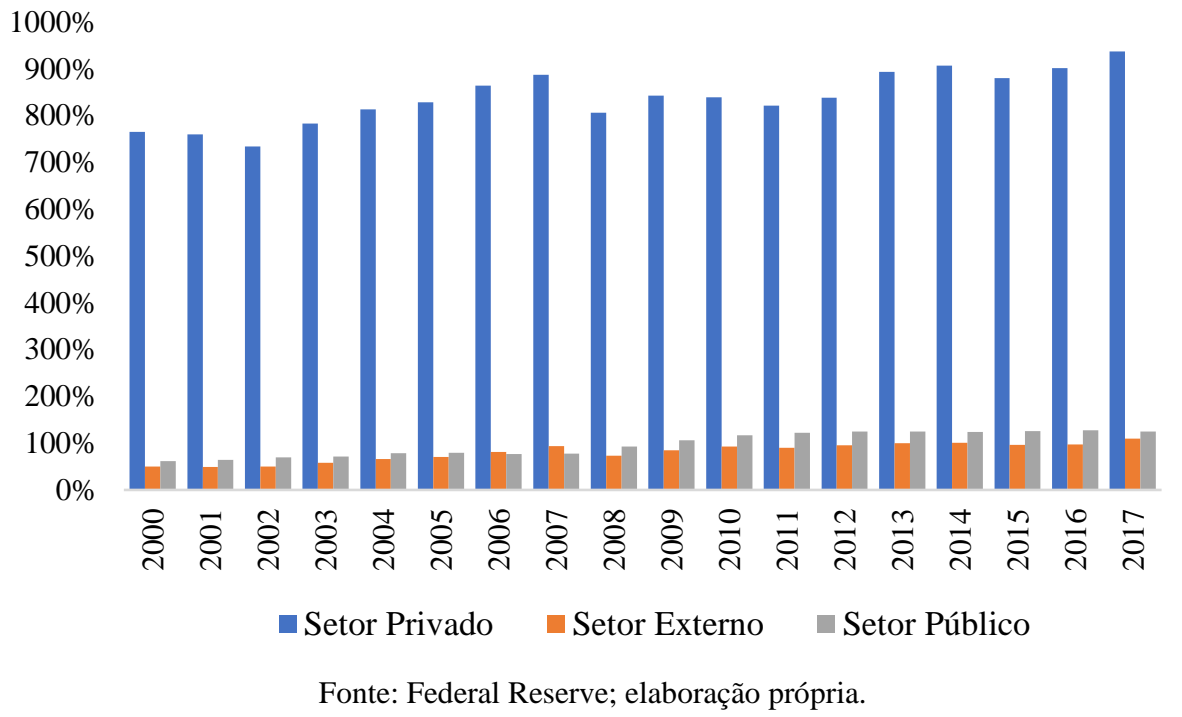

A principal consequência dos processos acima é evidenciada pelo Gráfico 3. De 2000 a 2007, observa-se a expansão dos passivos privados (incluso capital de terceiros), de pouco mais de $700 \%$ para quase $900 \%$ do PIB. A queda do passivo privado em 2008 e a estabilidade até 2011 é consequência da desvalorização dos ativos privados causados pela crise de 2008 e pelo processo de substituição de dívidas privadas podres por dívida pública líquida, que cresceu de pouco menos de $100 \%$ para mais de $120 \%$ no período. De 2012 a 2017, observa-se um novo processo de endividamento privado, que levou o passivo deste setor crescer acima de $900 \%$ do PIB, reduzindo sistematicamente os superávits privados (Gráfico 2).

É interessante observar que a dívida privada é significativamente superior à dívida pública, sendo que as crises financeiras estão associadas à redução da liquidez dos passivos privados (GUTTMANN, 2015). Nesses momentos, os agentes privados contraem significativamente suas variáveis de gasto agregado, reduzindo a demanda e o ritmo de crescimento do PIB (CARDIM DE CARVALHO, 2013). Ou seja, as variáveis mais relevantes para a compreensão de crises financeiras como a de 2008 estão ausentes no NCM. 


\section{Conclusão}

O presente artigo sumarizou os principais elementos teórico-estatísticos do NCM que incorporam ideias Novo-Clássicas e Novo-Keynesianas. Após a crise de 2008, dada a incapacidade dos modelos econômicos do NCM em prever e explicar as razões da turbulência financeiras e de seus impactos macroeconômicos, foram levantados questionamentos acerca dessa construção teórica e seu peso na ciência econômica. No entanto, como afirma Pedrosa e Farhi (2015), o NCM ainda permanece como a vertente econômica principal do mainstream econômico e ditou a formulação das políticas econômicas até então.

Em paralelo, novas vertentes pertencentes à heterodoxia econômica foram se estruturando ao longo da década de 2000, construindo um escopo teórico capaz de explicar os ciclos econômicos de expansão e retração das variáveis de demanda agregada com base nas relações financeiras entre agentes econômicos. Nesse sentido, destaca-se o elevado nível de endividamento privado, e não público, como elemento capaz de explicar as crises econômicas e que contribui para esclarecer a realidade econômica atual dos EUA.

Nesse aspecto, não haveria empecilho significativo para a retomada da política fiscal mais ativa. Blanchard e Summers (2017) chegam à conclusão dessa necessidade, mesmo que seus modelos não sejam capazes de inferir tal necessidade. Por outro lado, a bibliografia pós-Keynesiana evidencia que, em um cenário de baixa taxa de juros e baixa inflação, uma política fiscal mais ativa seria capaz de elevar o crescimento do PIB sem gerar alterações significativas na razão Dívida/PIB (GODLEY, LAVOIE, 2007). 


\section{Referências}

ALVES, S. A. L.; CORREA, A. DA S. Um Conto de Três Hiatos: Desemprego, Utilização da Capacidade Instalada da Indústria e Produto: Trabalhos para Discussão. Brasília: Banco Central do Brasil, dez. 2013.

AMITRANO, C. Regime de crescimento, restrição externa e financeirização; uma proposta de conciliação. Economia e Sociedade, v. 22, n. 2, p. 285-316, 2013.

DOI: https://doi.org/10.1590/S0104-06182013000200001

BARRO, R. J. Are Government Bonds Net Wealth? Journal of Political Economy, v. 82, n. 6, p. 1095-1117, 1974. DOI: https://doi.org/10.1086/260266

BARRO, R. J. The Ricardian Approach to Budget Deficits. Journal of Economic Perspectives, v. 3, n. 2, p. 37-54, 1989. DOI: http://doi.org/10.1257/jep.3.2.37

BLANCHARD, O. Fiscal Dominance and Inflation Targeting: Lessons from Brazil. Cambridge, MA: National Bureau of Economic Research, mar. 2004. Disponível em: <http://www.nber.org/papers/w10389.pdf>. Acesso em: 12 set. 2018.

BLANCHARD, O.; DELL'ARICCIA, G.; MAURO, P. Rethinking Macroeconomic Policy. Journal of Money, Credit and Banking, v. 42, p. 199-215, 18 ago. 2010.

BLANCHARD, O.; DELL'ARICCIA, G.; MAURO, P. Rethinking Macro Policy II: Getting Granular. Washington: International Monetary Fund, 2013.

BLANCHARD, O; SUMMERS, L. Rethinking Stabilization Policy: Evolution or Revolution? n. October, p. 0-24, 2017. DOI: http://doi.org/10.3386/w24179

BOYER, R. Is a finance-led growtIs a Finance-led growth regime a viable alternative to Fordism? A preliminary analysis. Economy and Society, v. 29, n. 1, p. 111-145, 2000. DOI: https://doi.org/10.1080/030851400360587

BOYER, R. The euro crisis: Undetected by conventional economics, favoured by nationally focused polity. Cambridge Journal of Economics, v. 37, n. 3, p. 533-569, 2013. DOI: http://doi.org/10.1093/cje/bet013

BRUNNERMEIER, M.; SANNIKOV, Y. A Macroeconomic Model with a Financial Sector. American Economic Review, v. 104, n. 2, p. 379-421, 2014.

DOI: http://doi.org/10.1257/aer.104.2.379

CAIANI, A. et al. Agent based-stock flow consistent macroeconomics: Towards a benchmark model. Journal of Economic Dynamics and Control, v. 69, p. 375-408, 2016. DOI: https://doi.org/10.1016/j.jedc.2016.06.001

CARDIM DE CARVALHO, F. J. Keynes and the endogeneity of money. Review of Keynesian Economics, v. 1, n. 4, p. 431-446, 2013.

DOI: http://doi.org/10.4337/roke.2013.04.05 
COUTINHO, L.; BELLUZZO, L. G. "Financeirização" da riqueza, inflação de ativos e decisões de gasto em economias abertas. Economia e Sociedade, v. 11, n. 4, p. 137-150, 1998.

CÚRDIA, V.; WOODFORD, M. The central-bank balance sheet as an instrument of monetarypolicy. Journal of Monetary Economics, v. 58, n. 1, p. 54-79, jan. 2011. DOI: https://doi.org/10.1016/j.jmoneco.2010.09.011

DAVIDSON, P. A technical definition of uncertainty and the long-run non-neutrality of money. Cambridge Journal of Economics, v. 12, n. 3, p. 329-337, 1988.

DOI: https://doi.org/10.1093/oxfordjournals.cje.a035063

DOSI, G. et al. Fiscal and monetary policies in complex evolving economies. Journal of Economic Dynamics and Control, v. 52, p. 166-189, 2015.

DOI: https://doi.org/10.1016/j.jedc.2014.11.014

FAGIOLO, G.; ROVENTINI, A. Macroeconomic Policy in DSGE and Agent-Based Models. Revue de l'OFCE, v. 124, n. 5, p. 67, 2012.

DOI: https://doi.org/10.3917/reof.124.0067

FAMA, E. F. Banking in the Theory of Finance. Journal of Monetary Economics, v. 6, p. 39-57, 1980. DOI: https://doi.org/10.1016/0304-3932(80)90017-3

FARHI, M. Crise Financeira e Reformas da Supervisão e Regulação: Texto para Discussão. Brasília: Ipea, 2011.

FARHI, M.; CINTRA, M. A. M. A arquitetura do sistema financeiro internacional contemporâneo. Revista de Economia Política, v. 29, n. 3, p. 274-294, set. 2009. DOI: http://dx.doi.org/10.1590/S0101-31572009000300017

FONTANA, G. Why money matters: Wicksell, Keynes, and the new consensus view on monetary policy. Journal of Post Keynesian Economics, v. 30, p. 43-60, 1 out. 2007. DOI: http://doi.org/10.2753/PKE0160-3477300102

GODLEY, W. Seven Unsustainable Processes: Medium-Term Prospects and Policies for the United States and the World. In: LAVOIE, M.; ZEZZA, G. (Eds.). . The Stock-Flow Consistent Approach. London: Palgrave Macmillan UK, 2012. p. 216-254.

GOODFRIEND, M.; KING, R. G. The New Neoclassical Synthesis and the Role of Monetary Policy. In: BERNANKE, BEN S; ROTEMBERG, JULIO (Eds.). . NBER Macroeconomics Annual 1997. [s.1.] MIT Press, 1997. v. 12p. 361.

GURLEY, J. G.; SHAW, E. S. Financial aspects of economic development. The American Economic Review, v. 45, n. 4, p. 515-538, 1955.

GURLEY, J. G.; SHAW, E. S. Financial Intermediaries and the Saving-Investment Process. The Journal of Finance, v. 11, n. 2, p. 257-276, 1956.

DOI: https://doi.org/10.2307/2976705 
GUTTMANN, R. The heterodox notion of structural crisis. Review of Keynesian Economics, v. 3, n. 2, p. 194-212, abr. 2015.

DOI: http://doi.org/10.4337/roke.2015.02.04

GUTTMANN, R.; PLIHON, D. Consumer debt and financial fragility. International Review of Applied Economics, v. 24, n. 3, p. 269-283, 2010.

DOI: https://doi.org/10.1080/02692171003701420

HEIN, E. "Financialization," distribution, capital accumulation, and productivity growth in a post-Kaleckian model. Journal of Post Keynesian Economics, v. 34, n. 3, p. 475496, 2012. DOI: https://doi.org/10.2753/PKE0160-3477340305

HERNDON, T.; ASH, M.; POLLIN, R. Does high public debt consistently stifle economic growth? A critique of Reinhart and Rogoff. Cambridge Journal of Economics, v. 38, n. 2, p. 257-279, 2014. DOI: https://doi.org/10.1093/cje/bet075

MILLER, M.; MODIGLIANI, F. Dividend Policy, Growth, and the Valuation of Shares. The Journal of Business, v. 34, n. 4, p. 411-433, 1961.

DOI: http://doi.org/10.1086/294442

MINSKY, H. P. Stabilizing an Unstable Economy. New Haven: McGraw-Hill, 2008.

MODIGLIANI, F.; MILLER, M. The Cost of Capital, Corporation Finance and the Theory of Investment. The American Economic Review, v. 48, n. 3, p. 261-297, 1958.

NIKIFOROS, M.; ZEZZA, G. Stock-Flow Consistent Macroeconomic Model: A Survey. Journal of Economic Surveys, v. 31, n. 5, p. 1204-1239, dez. 2017.

DOI: https://doi.org/10.1111/joes.12221

PASINETTI, L. L. A few counter-factual hypotheses on the current economic crisis.

Cambridge Journal of Economics, v. 36, n. 6, p. 1433-1453, 2012.

DOI: https://doi.org/10.1093/cje/ber009

PEDROSA, Í.; FARHI, M. Macroeconomic theory in the aftermath of the crisis:

Mainstream and new keynesianism. Nova Economia, v. 25, n. 2, p. 237-260, 2015.

DOI: https://doi.org/10.1590/0103-6351/1737

PRATES, D. M.; FARHI, M. The shadow banking system and the new phase of the money manager capitalism. Journal of Post Keynesian Economics, v. 37, p. 568-589, 24 jul. 2015. DOI: https://doi.org/10.1080/01603477.2015.1049925

REINHART, B. C. M.; ROGOFF, K. S. Growth in a Time of Debt. The American Economic Review, v. 100, n. 2, p. 573-578, 2010. DOI: http://doi.org/10.3386/w15639

SOUZA, L. F. Escolhas Alocativas e Alavancagem: As Transformações no Sistema Financeiro dos Estados Unidos e seus Impactos Macroeconômicos. Campinas: Universidade Estadual de Campinas, fev. 2016. 
STIGLITZ, J. E. Rethinking Macroeconomics: What Went Wrong and How to Fix It:

Rethinking Macroeconomics. Global Policy, v. 2, n. 2, p. 165-175, maio 2011.

DOI: https://doi.org/10.1111/j.1758-5899.2011.00095.x

STOCKHAMMER, E. Financialisation and the slowdown of accumulation. Cambridge Journal of Economics, v. 28, n. 5, p. 719-741, 2004.

DOI: https://doi.org/10.1093/cje/beh032

TAYLOR, J. B. Discretion versus policy rules in practice. Carnegie-Rochester

Conference Series on Public Policy, v. 39, p. 195-214, dez. 1993.

DOI: https://doi.org/10.1016/0167-2231(93)90009-L

VAN TREECK, T. A synthetic, stock-flow consistent macroeconomic model of "financialisation". Cambridge Journal of Economics, v. 33, n. 3, p. 467-493, 2009.

DOI: https://doi.org/10.1093/cje/ben039

WASMER, E.; WEIL, P. The Macroeconomics of Labor and Credit Market Imperfections. American Economic Review, v. 94, n. 4, p. 944-963, ago. 2004. DOI: http://doi.org/10.1257/0002828042002525

WOODFORD, M. Interest and Prices: Foundations of a Theory of Monetary Policy. New Jersey: Princenton University Press, 2003.

WOODFORD, M. How Important Is Money in the Conduct of Monetary Policy? Journal of Money, Credit and Banking, v. 40, n. 8, p. 1561-1598, 2008.

DOI: http://doi.org/10.3386/w13325

WOODFORD, M. Convergence in Macroeconomics: Elements of the New Synthesis. American Economic Journal: Macroeconomics, v. 1, n. 1, p. 267-279, 2009. DOI: http://doi.org/10.1257/mac.1.1.267

WRAY, L. R. The rise and fall of money manager capitalism: A Minskian approach. Cambridge Journal of Economics, v. 33, n. 4 SPEC. ISS., p. 807-828, 2009. DOI: https://doi.org/10.1093/cje/bep024 